\title{
Tolerância do feijoeiro a herbicidas aplicados na cultura da cana-de-açúcar ${ }^{1}$
}

\author{
Common bean tolerance to herbicides applied in sugarcane crop
}

Camila Pereira Caixeta Fernandes ${ }^{2}$, Antônio Joaquim Braga Pereira Braz ${ }^{2}$, Sergio de Oliveira Procópio $^{3}$, Hugo de Almeida Dan ${ }^{4}$, Guilherme Braga Pereira Braz ${ }^{4}$, Alberto Leão de Lemos Barroso $^{2}$, Carlos César Evangelista de Menezes ${ }^{2}$, Gustavo André Simon ${ }^{2}$, Lucas Braga Pereira $\mathrm{Braz}^{2}$

Resumo - O trabalho teve como objetivo avaliar a seletividade dos principais herbicidas utilizados na cultura da cana-de-açúcar, aplicados em pré ou pós-emergência, ao feijão-comum (Grupo Jalo - cultivar Jalo Precoce). Na modalidade de pré-emergência os tratamentos avaliados foram: ametryn $\left(2.500 \mathrm{~g} \mathrm{ha}^{-1}\right)$, tebuthiuron $\left(800 \mathrm{~g} \mathrm{ha}^{-1}\right)$, [hexazinone + diuron] $(237,6+842,4 \mathrm{~g}$ $\left.\mathrm{ha}^{-1}\right)$, metribuzin $\left(1.440 \mathrm{~g} \mathrm{ha}^{-1}\right)$, clomazone $\left(800 \mathrm{~g} \mathrm{ha}^{-1}\right)$, isoxaflutole $\left(112,5 \mathrm{~g} \mathrm{ha}^{-1}\right)$, sulfentrazone (600 $\left.\mathrm{g} \mathrm{ha}^{-1}\right)$, imazapic (105 $\left.\mathrm{g} \mathrm{ha}^{-1}\right)$, trifluralin $\left(1.800 \mathrm{~g} \mathrm{ha}^{-1}\right)$ e S-metolachlor (1.920 $\left.\mathrm{g} \mathrm{ha}^{-1}\right)$, mais uma testemunha sem aplicação. Já na modalidade de pós-emergência os tratamentos foram: MSMA (1.440 $\left.\mathrm{g} \mathrm{ha}^{-1}\right)$, MSMA + diuron $\left(1.080+420 \mathrm{~g} \mathrm{ha}^{-1}\right)$, [hexazinone + diuron] $(237,6+$ $\left.842,4 \mathrm{~g} \mathrm{ha}^{-1}\right)$, metribuzin $\left(1.440 \mathrm{~g} \mathrm{ha}^{-1}\right)$, ametryn $\left(1.500 \mathrm{~g} \mathrm{ha}^{-1}\right)$, [ametryn + trifloxysulfuron sodium] $\left(1.280+32,4 \mathrm{~g} \mathrm{ha}^{-1}\right)$, halosulfuron $\left(112,5 \mathrm{~g} \mathrm{ha}^{-1}\right), 2,4-\mathrm{D}\left(1.005 \mathrm{~g} \mathrm{ha}^{-1}\right)$ e mesotrione (120 $\left.\mathrm{g} \mathrm{ha}^{-1}\right)$, mais uma testemunha sem aplicação. Foram avaliadas a fitointoxicação, estande e altura de plantas, matéria verde e seca da parte aérea, número de plantas na colheita, altura de inserção da primeira vagem, além da produtividade. Os herbicidas S-metolachlor, tebuthiuron, trifluralin e clomazone apresentaram seletividade satisfatória às plantas de feijão cv. Jalo Precoce, quando aplicados em pré-emergência. No entanto, ametryn, [hexazinone + diuron], metribuzin, isoxaflutole, sulfentrazone e imazapic não foram seletivos, também em aplicações de préemergência. Nenhum dos herbicidas avaliados apresentou condições de seletividade para ser utilizado em pós-emergência em um sistema de cultivo integrado de feijão (cv. Jalo Precoce) em áreas de produção de cana-de-açúcar.

Palavras-chave: Saccharum spp., Phaseolus vulgaris, plantas daninhas.

Abstract - This work was aimed to evaluate the selectivity of main herbicides used in sugar cane crop applied in pre or post emergence conditions to common bean ("Jalo" Group - cultivar "Jalo Precoce"). In pre emergence modality the treatments evaluated consisted of: ametryn (2.500 $\left.\mathrm{g} \mathrm{ha}^{-1}\right)$, tebuthiuron $\left(800 \mathrm{~g} \mathrm{ha}^{-1}\right)$, [hexazinone + diuron] $\left(237.6+842.4 \mathrm{~g} \mathrm{ha}^{-1}\right)$, metribuzin $(1,440$ $\left.\mathrm{g} \mathrm{ha}^{-1}\right)$, clomazone $\left(800 \mathrm{~g} \mathrm{ha}^{-1}\right)$, isoxaflutole $\left(112.5 \mathrm{~g} \mathrm{ha}^{-1}\right)$, sulfentrazone $\left(600 \mathrm{~g} \mathrm{ha}^{-1}\right)$, imazapic (105 $\left.\mathrm{g} \mathrm{ha}^{-1}\right)$, trifluralin $\left(1,800 \mathrm{~g} \mathrm{ha}^{-1}\right)$, S-metolachlor $\left(1,920 \mathrm{~g} \mathrm{ha}^{-1}\right)$, and a check without herbicide application. In post emergence modality treatments evaluated were: MSMA $\left(1,440 \mathrm{~g} \mathrm{ha}^{-1}\right)$, MSMA + diuron $\left(1,080+420 \mathrm{~g} \mathrm{ha}^{-1}\right)$, [hexazinone + diuron] $\left(237.6+842.4 \mathrm{~g} \mathrm{ha}^{-1}\right)$, metribuzin

${ }^{1}$ Recebido para a publicação em 31/05/2011 e na forma revisada em 18/08/2011.

${ }^{2}$ FESURV - Universidade de Rio Verde;

${ }^{3}$ Embrapa Soja, email: <procopio.so@gmail.com>;

${ }^{4}$ Universidade Estadual de Maringá (UEM). 
$\left(1,440 \mathrm{~g} \mathrm{ha}^{-1}\right)$, ametryn $\left(1,500 \mathrm{~g} \mathrm{ha}^{-1}\right)$, [ametryn + trifloxysulfuron sodium] $\left(1,280+32.4 \mathrm{~g} \mathrm{ha}^{-1}\right)$, halosulfuron (112.5 $\left.\mathrm{g} \mathrm{ha}^{-1}\right), 2.4-\mathrm{D}\left(1,005 \mathrm{~g} \mathrm{ha}^{-1}\right)$ and mesotrione $\left(120 \mathrm{~g} \mathrm{ha}^{-1}\right)$ besides a check without herbicide application. Phytointoxication, stand, plant height, wet and dry matter of shoots, number of plants at harvest, height of first pod insertion, and grain yield were evaluated. S-metolachlor, tebuthiuron, trifluralin and clomazone herbicides showed satisfactory selectivity to bean plants cv. Jalo Precoce, when applied in pre-emergence. However, ametryn [hexazinone + diuron], metribuzin, isoxaflutole, sulfentrazone and imazapic were not selective, even in preemergence applications. None of tested herbicides showed selectivity conditions for being used in post-emergence in one bean integrated cultivation system (cv. Jalo Precoce) in areas with sugar cane crop production.

Key words: Saccharum spp., Phaseolus vulgaris, weeds.

\section{Introdução}

O Brasil é o maior produtor de cana-deaçúcar do mundo e grande expoente na tecnologia de produção de agroenergia, devendo aumentar muito suas exportações nos próximos anos (FNP - Consultoria e comércio, 2007). Para isso, novas unidades industriais estão sendo construídas em várias regiões do país, aumentando consideravelmente a área cultivada com cana-de-açúcar. Todavia, o aumento na produtividade associado à redução de custos e à sustentabilidade da produção são os grandes desafios da pesquisa nacional.

Entre as ações estratégicas propostas por Neves \& Conejero (2007) para aumentar a sustentabilidade do agroenogócio da cana-deaçúcar, destacam-se: estimular a integração e diversificação da agricultura voltada para a produção de alimentos e energia, mediante aplicação de tecnologias; explorar a sinergia entre os dois tipos de plantio (energia e alimentos), desmistificando a visão de concorrência entre estes.

O feijoeiro é uma cultura de grande importância social no Brasil, sendo, geralmente, cultivado em consórcio com o milho. No sistema de consórcio, duas ou mais culturas utilizam o mesmo terreno num espaço de tempo. O feijoeiro, por ser uma cultura de ciclo vegetativo curto, apresentar certa tolerância à competição e se constituir um alimento básico para o consumo do agricultor, é muito utilizado neste sistema. Na América Latina, $80 \%$ da produção de feijão ocorrem em plantios consorciados, principalmente com o milho (Francis et al., 1982). De acordo com Hungria et al. (1997), freqüentemente a produtividade do feijoeiro consorciado com milho supera a da monocultura. Hungria et al. (1997) também constataram que o cultivo do feijoeiro em monocultura ou em consórcio com o milho incrementa, em relação à monocultura de milho, a biomassa microbiana, o número de células, a biodiversidade de Rhizobium e o número de espécies de fungos micorrízicoarbusculares.

O cultivo consorciado da cana-deaçúcar e feijão é viável em regiões onde as culturas podem ser plantadas simultaneamente. Desse modo, é possível obter uma safra de feijão entre as fileiras de cana-de-açúcar, aumentando a eficiência do uso da terra, sem reduzir significativamente a produção em relação aos cultivos solteiros (Comissão Estadual de Pesquisa de Feijão, 2000).

O controle das plantas daninhas nos canaviais é uma das práticas de manejo obrigatórias. Para isso o controle químico é o método mais utilizado, em razão das grandes áreas plantadas, da eficiência e do alto rendimento, aliado ao baixo custo em relação a outros métodos de controle e, também, por haver no mercado vários herbicidas registrados para essa cultura no Brasil (Procópio et al., 2004; Christoffoleti et al., 2006). 
Tanto para a cana-de-açúcar, como para qualquer outra espécie cultivada, a recomendação de um herbicida está condicionada a sua seletividade, ou seja, a sua capacidade de eliminar espécies vegetais indesejáveis sem promover reduções economicamente significativas, tanto na qualidade quanto na quantidade produzida pela cultura (Velini et al. 2000). A seletividade a herbicidas não pode ser determinada apenas pela verificação ou não de sintomas de intoxicação, pois já são conhecidos exemplos de produtos que podem reduzir a produtividade das culturas sem causarem efeitos visualmente detectáveis e, também, outros que provocam injúrias acentuadas, mas que permitem a recuperação plena da cultura (Silva et al., 2003). Dessa forma, quando o objetivo for avaliar os efeitos de herbicidas sobre espécies cultivadas, é fundamental que, além de avaliar as injúrias provocadas por eles, seja incluída a taxa de crescimento e a produtividade da cultura (Velini et al., 2000).

Decorrente desse cenário, o trabalho teve como objetivo avaliar a seletividade dos principais herbicidas utilizados na cultura da cana-de-açúcar, aplicados em pré ou pósemergência, ao feijão-comum (Grupo Jalo cultivar Jalo Precoce).

\section{Material e Métodos}

O trabalho constou de dois ensaios. No primeiro, foram alocados apenas tratamentos aplicados em pré-emergência, e no segundo, os tratamentos aplicados em pós-emergência. Os ensaios foram instalados no município de Rio Verde-GO, cujas coordenadas geográficas são: latitude $17^{\circ} 45^{\prime} 57,3 \mathrm{~S}$, longitude $51^{\circ} 02^{\prime}$ 05,9"W e altitude de 838 metros, durante o período de novembro de 2008 a abril de 2009. O clima, conforme classificação de Köppen é do tipo CWA, tropical de savana, classificado também como úmido, e possui inverno seco, com precipitação média anual de $1.500 \mathrm{~mm}$ e temperatura média anual de $25^{\circ} \mathrm{C}$. O solo da área experimental foi identificado como Latossolo Vermelho distrófico. Na Tabela 1 são apresentados os resultados da análise química e física do solo, coletado entre 0 a 40 $\mathrm{cm}$ de profundidade.

Não foi realizado nenhum manejo químico das plantas daninhas presentes na área, anteriormente a semeadura dos ensaios, realizando-se apenas uma operação mecânica com o equipamento agrícola, "triton", para triturar parcialmente da palhada de milho que se encontrava na área antes da implantação.

Tabela 1. Caracterização química e física do solo da área experimental nas profundidades de 010, 10-20 e 20-40 cm. Rio Verde-GO. 2008.

\begin{tabular}{cccccccccccc}
\hline $\begin{array}{c}\text { Profundidade } \\
\mathrm{cm}\end{array}$ & $\begin{array}{c}\mathrm{pH} \\
\mathrm{CaCl}_{2} \\
0,01 \mathrm{M}\end{array}$ & $\begin{array}{c}\mathrm{Ca} \\
\text {--------cmolc }\end{array}$ & $\mathrm{Mg}$ & $\mathrm{Al}$ & $\mathrm{H}+\mathrm{Al}$ & $\mathrm{K}$ & $\mathrm{P}$ (Mellich) & M.O. & Argila & Silte & Areia \\
\hline & & & & & & & & & & & \\
$0-10$ & 4,50 & 2,52 & 0,76 & 0,01 & 4,1 & 77 & 8,99 & 28,34 & 52 & 5 & 43 \\
$10-20$ & 4,30 & 1,60 & 0,42 & 0,05 & 4,1 & 59 & 7,13 & 23,88 & 55 & 3 & 42 \\
$20-40$ & 4,30 & 0,96 & 0,23 & 0,20 & 5,9 & 35 & 1,89 & 17,84 & 54 & 3 & 43 \\
\hline
\end{tabular}

O cultivar de feijão Jalo Precoce, com ciclo médio de 70 dias foi semeado no dia 17 de dezembro de 2008, em espaçamento de 0,5 $\mathrm{m}$, de forma mecanizada, sendo a máquina regulada para distribuir 14 sementes por metro, o que resultou em uma densidade de semeadura de 280.000 sementes $^{-1}{ }^{-1}$. A profundidade de semeadura utilizada foi de $4 \mathrm{~cm}$, e a adubação de base com $32 \mathrm{~kg} \mathrm{ha}^{-1}$ de $\mathrm{N}$ (sulfato de amônio), $80 \mathrm{~kg} \mathrm{ha}^{-1}$ de $\mathrm{P}_{2} \mathrm{O}_{5}$ (superfosfato 
simples) e $72 \mathrm{~kg} \mathrm{ha}^{-1}$ de $\mathrm{K}_{2} \mathrm{O}$ (cloreto de potássio). Uma adubação de cobertura foi realizada com $90 \mathrm{~kg} \mathrm{ha}^{-1}$ de $\mathrm{N}$ aos 35 dias após a emergência das plantas de feijão. Os demais tratos culturais foram convencionais, seguindo as recomendações da Embrapa (2008).

Os ensaios foram instalados no delineamento de blocos casualizados, com quatro repetições. As parcelas experimentais foram formadas por seis linhas da cultura espaçadas em $0,5 \mathrm{~m}$, e com $5 \mathrm{~m}$ de comprimento, totalizando uma área de $15 \mathrm{~m}^{2}$. No entanto, para fins de avaliação, foram consideradas as quatro linhas centrais, descartando-se $0,5 \mathrm{~m}$ de cada extremidade, resultando área útil de $8 \mathrm{~m}^{2}$. Todas as parcelas experimentais, independentemente da aplicação de herbicidas, foram mantidas livres da infestação de plantas daninhas, por meio de constantes capinas manuais.

\section{Bioensaio em campo com aplicações de herbicidas em pré-emergência}

Para o ensaio em pré-emergência os tratamentos foram formados por 10 herbicidas: ametryn (2.500 $\left.\mathrm{g} \mathrm{ha}^{-1}\right)$, tebuthiuron (800 $\mathrm{g} \mathrm{ha}^{-}$ $\left.{ }^{1}\right)$, [hexazinone + diuron] $\left(237,6+842,4 \mathrm{~g} \mathrm{ha}^{-}\right.$ $\left.{ }^{1}\right)$, metribuzin $\left(1.440 \mathrm{~g} \mathrm{ha}^{-1}\right)$, clomazone $(800 \mathrm{~g}$ $\left.\mathrm{ha}^{-1}\right)$, isoxaflutole $\left(112,5 \mathrm{~g} \mathrm{ha}^{-1}\right)$, sulfentrazone (600 $\left.\mathrm{g} \mathrm{ha}^{-1}\right)$, imazapic (105 $\left.\mathrm{g} \mathrm{ha}^{-1}\right)$, trifluralin (1.800 $\mathrm{g} \mathrm{ha}^{-1}$ ) e S-metolachlor (1.920 $\left.\mathrm{g} \mathrm{ha}^{-1}\right)$, mais uma testemunha sem aplicação.

A aplicação dos tratamentos herbicidas em pré-emergência foi realizada um dia após a semeadura do feijão, utilizando-se um pulverizador costal com pressurização por $\mathrm{CO}_{2}$, munido de barra de $2 \mathrm{~m}$, contendo quatro pontas de pulverização do tipo AI 110-02 (0,5 $\mathrm{m}$ entre pontas), regulado para atuar com pressão de serviço de 2,5 $\mathrm{kgf} \mathrm{cm}^{-2}$, proporcionando volume de calda equivalente a $150 \mathrm{~L} \mathrm{ha}^{-1}$. A aplicação foi iniciada às 8:29 h com término às $12: 47 \mathrm{~h}$. As condições ambientais no momento da aplicação foram as seguintes: temperatura média de $26,8^{\circ} \mathrm{C}$, temperatura mínima de $23,7^{\circ} \mathrm{C}$, temperatura máxima de $27,6^{\circ} \mathrm{C}$, UR média de $67 \%$ e velocidade do vento média de $2,1 \mathrm{~km} \mathrm{~h}^{-1}$.

Durante a condução do ensaio foram realizadas as seguintes avaliações: fitointoxicação, avaliada visualmente, aos 7, 14, 28, 42 e 56 dias após a aplicação (DAA), utilizando escala percentual, onde 0 (zero) representa ausência de sintomas e 100 (cem) morte de todas as plantas presentes na área útil da parcela; estande de plantas aos 10 dias após a emergência (DAE), por meio da contagem de plantas emergidas em 2 metros; altura de plantas aos 25 e 60 DAE, utilizando trena graduada, tomando como base das medições a distância entre a região do coleto até $\mathrm{o}$ meristema apical de 10 plantas por parcela.

Também foram realizadas avaliações da matéria verde da parte aérea aos 30 e 60 DAE, onde 10 plantas por parcela foram cortadas rente ao solo, sendo pesadas imediatamente após a coleta; matéria seca da parte aérea aos 30 e 60 DAE, onde as 10 plantas coletadas para a avaliação da matéria verde foram secadas em estufa de circulação forçada de ar, com temperatura de $70 \pm 3^{\circ} \mathrm{C}$, por $72 \mathrm{~h}$; número de plantas na colheita, contabilizando todas as plantas presentes na área útil das parcelas no momento da colheita; altura de inserção da primeira vagem de 10 plantas por parcela; e produtividade, colhendo-se todas as plantas presentes na área útil das parcelas, sendo a umidade de grãos padronizada para $13 \%$.

\section{Bioensaio em campo com aplicações de herbicidas em pós-emergência}

Para o ensaio em pós-emergência os tratamentos foram formados por nove herbicidas: MSMA (1.440 $\left.\mathrm{g} \mathrm{ha}^{-1}\right)$, MSMA + diuron $\left(1.080+420 \mathrm{~g} \mathrm{ha}^{-1}\right)$, [hexazinone + diuron] $\left(237,6+842,4 \mathrm{~g} \mathrm{ha}^{-1}\right)$, metribuzin (1.440 $\left.\mathrm{g} \mathrm{ha}^{-1}\right)$, ametryn $\left(1.500 \mathrm{~g} \mathrm{ha}^{-1}\right)$, [ametryn + trifloxysulfuron sodium] $\left(1.280+32,4 \mathrm{~g} \mathrm{ha}^{-}\right.$ $\left.{ }^{1}\right)$, halosulfuron (112,5 $\left.\mathrm{g} \mathrm{ha}^{-1}\right), 2,4-\mathrm{D}(1.005 \mathrm{~g}$ 
$\mathrm{ha}^{-1}$ ) e mesotrione (120 $\left.\mathrm{g} \mathrm{ha}^{-1}\right)$, mais uma testemunha sem aplicação.

A aplicação dos tratamentos herbicidas em pós-emergência foi realizada 30 dias após a semeadura do feijão, utilizando-se um pulverizador costal com pressurização por $\mathrm{CO}_{2}$, munido de barra de $2 \mathrm{~m}$, contendo quatro pontas de pulverização do tipo AI 110-02 (0,5 $\mathrm{m}$ entre pontas), regulado para atuar com pressão de serviço de 2,5 $\mathrm{kgf} \mathrm{cm}^{-2}$, proporcionando volume de calda equivalente a $150 \mathrm{~L} \mathrm{ha}^{-1}$. A aplicação foi iniciada às 9:00 h com término às 10:45 h. As condições ambientais no momento da aplicação foram as seguintes: temperatura média de $25,6^{\circ} \mathrm{C}$, temperatura mínima de $22,7^{\circ} \mathrm{C}$, temperatura máxima de $27,6^{\circ} \mathrm{C}$, UR média de $72 \%$ e velocidade do vento média de $4,3 \mathrm{~km} \mathrm{~h}^{-1}$.

Durante a condução do ensaio foram realizadas as seguintes avaliações: fitointoxicação, avaliada visualmente, aos 7, 14 e 28 dias após a aplicação (DAA), utilizando escala percentual, onde 0 (zero) representa ausência de sintomas e 100 (cem) morte de todas as plantas presentes na área útil da parcela; altura de plantas aos 22 DAA, utilizando trena graduada, tomando como base das medições a distância entre a região do coleto até o meristema apical de 10 plantas por parcela.

Também foram realizadas avaliações da matéria verde da parte aérea aos 22 DAA, onde 10 plantas por parcela foram cortadas rente ao solo, sendo pesadas imediatamente após a coleta; matéria seca da parte aérea aos 22 DAA, onde as 10 plantas coletadas para a avaliação da matéria verde foram secadas em estufa de circulação forçada de ar, com temperatura de $70 \pm 3^{\circ} \mathrm{C}$, por $72 \mathrm{~h}$; número de plantas na colheita, contabilizando todas as plantas presentes em $8 \mathrm{~m}^{2}$ da área útil das parcelas no momento da colheita; altura de inserção da primeira vagem de 10 plantas por parcela; e produtividade, colhendo-se todas as plantas presentes na área útil das parcelas, sendo a umidade de grãos padronizada para $13 \%$.

Os resultados de cada ensaio foram analisados separadamente. Os dados foram submetidos a uma transformação $(\sqrt{ } \mathrm{x}+1)$ para seguir os pressupostos necessários para a análise de variância, que foi realizada com o programa estatístico Sisvar (Ferreira, 1998). As médias das variáveis significativas foram agrupadas utilizando-se o critério de Scott Knott a 5\% de significância.

\section{Resultados e Discussão}

Bioensaio em campo com aplicações de herbicidas em pré-emergência

Com exceção do trifluralin, os demais tratamentos promoveram níveis de intoxicação significativos nas plantas de feijão na primeira avaliação (Tabela 2). Os herbicidas metribuzin, isoxaflutole, ametryn e [hexazinone + diuron] apresentaram os maiores níveis de intoxicação, sendo que nas parcelas que receberam metribuzin e isoxaflutole não se detectou nenhuma planta de feijão viva ou mesmo emergida. Esses mesmos tratamentos continuaram aos 14 DAA apresentando os níveis mais elevados de fitotoxicidade. Nessa avaliação todos os herbicidas promoveram um grau de intoxicação que diferiu significativamente do tratamento controle, destacando que o menor nível ainda continuou sendo do tratamento trifluralin $(10,7 \%)$ (Tabela 2). Salienta-se que aos 14 DAA os herbicidas imazapic e sulfentrazone acarretaram também em injúria elevada às plantas de feijão, superiores a de $70 \%$.

O mesmo panorama relatado aos 14 DAA se manteve aos 28 DAA com uma tendência de pequeno agravamento dos sintomas de intoxicação, contudo ressalta-se um início de recuperação das plantas semeadas onde foram aplicados os herbicidas tebuthiuron, clomazone e S-metolachlor (Tabela 2). Destaca-se que S-metolachlor juntamente com o trifluralin são os únicos 
herbicidas do ensaio que além de serem registrados para uso na cana-de-açúcar, também apresentam registro para utilização na cultura do feijão.

Aos 42 DAA, observou-se que os sintomas decorrentes da utilização dos herbicidas tebuthiuron, clomazone, sulfentrazone e S-metolachlor perderam intensidade, sendo que as injúrias observadas após a utilização do tebuthiuron, clomazone e S-metolachlor já se encontravam em níveis considerados como aceitáveis. Exceção a essa regra foram os efeitos causados pelos herbicidas imazapic e [hexazinone + diuron] nas plantas de feijão, que se agravaram nessa avaliação, ultrapassando dos $90 \%$ e se equiparando estatisticamente aos tratamentos metribuzin, isoxaflutole e ametryn (Tabela 2). Problemas de fitotoxicidade às plantas de feijão são comumente verificados após a aplicação de herbicidas. Vários fatores podem estar relacionados com esse fato, como: tipo de solo, precipitações, manejo da irrigação, temperatura e cultivar utilizado (Fuentes et al., 1984; Viger et al., 1991; Kunkel et al., 1996).

$\mathrm{Na}$ última avaliação de fitotoxicidade realizada aos 56 DAA, constatou-se que o tratamento que promoveu o menor nível de intoxicação foi s-metolachlor, comportamento que ficou evidente em quase todas as avaliações realizadas. Também, salienta-se que nessa avaliação, além do já relatado para metribuzin e isoxaflutole aos 7 DAA, todas as plantas de feijão presentes na área útil das parcelas que receberam ametryn e [hexazinone + diuron] estavam mortas, e muito poucas sobreviveram após o uso do imazapic (Tabela 2). Faz-se o relato de que os herbicidas metribuzin e imazapic apresentam registro para uso nas culturas da soja e do amendoim, duas espécies de leguminosas também cultivadas comercialmente como o feijão. Os herbicidas trifluralin, tebuthiuron e clomazone assim como o S-metolachlor, apresentaram, nessa última avaliação, níveis de intoxicação que demonstram potencial de serem seletivos ao feijoeiro cv. Jalo Precoce.

Os herbicidas imazapic, trifluralin, clomazone, [hexazinone + diuron], $\mathrm{S}$ metolachlor e tebuthiuron não promoveram reduções no estande de plantas de feijão contabilizado aos 10 dias após a emergência (DAE) (Tabela 3). Nas áreas onde se aplicou ametryn, metribuzin e isoxaflutole em préemergência, pouquíssimas plantas foram encontradas. Apesar de não tão severo, como observado nas áreas de ametryn, metribuzin e isoxaflutole, quando se aplicou o tratamento [hexazinone + diuron] e sulfentrazone se constatou menor número de plantas de feijão em relação ao tratamento controle.

Os tratamentos tebuthiuron, trifluralin, clomazone e S-metolachlor não ocasionaram redução na altura das plantas de feijão aos 25 DAE (Tabela 3). No entanto, sulfentrazone e imazapic promoveram inibição do crescimento das plantas de feijão, com destaque para a forte redução da altura das plantas presentes na área que recebeu o imazapic. Nos tratamentos com metribuzin, ametryn, isoxaflutole e [hexazinone + diuron] não foi possível a realização dessa avaliação pela ausência de plantas. 
Tabela 2. Fitointoxicação em plantas de feijoeiro cv. Jalo Precoce após aplicação em préemergência de herbicidas registrados para cultura da cana-de-açúcar. Rio Verde, GO. 2008/2009.

\begin{tabular}{lcccccc}
\hline Herbicida & $\begin{array}{c}\text { Dosagem } \\
\left(\mathrm{g} \mathrm{ha}^{-1}\right)\end{array}$ & \multicolumn{5}{c}{ Fitointoxicação (\%) } \\
\cline { 3 - 6 } & 2.500 & $7 \mathrm{DAA}^{*}$ & $14 \mathrm{DAA}$ & $28 \mathrm{DAA}$ & $42 \mathrm{DAA}$ & $56 \mathrm{DAA}$ \\
\hline ametryn & 800 & $4,0 \mathrm{a}$ & $93,2 \mathrm{a}$ & $97,2 \mathrm{a}$ & $97,2 \mathrm{a}$ & $100,0 \mathrm{a}$ \\
tebuthiuron & 900 & $38,7 \mathrm{c}$ & $41,0 \mathrm{c}$ & $26,0 \mathrm{c}$ & $12,7 \mathrm{c}$ & $10,0 \mathrm{c}$ \\
clomazone & 112,5 & $100,0 \mathrm{a}$ & $100,0 \mathrm{a}$ & $100,0 \mathrm{a}$ & $100,0 \mathrm{a}$ & $100,0 \mathrm{a}$ \\
isoxaflutole & $237,5+842,4$ & $85,7 \mathrm{a}$ & $91,0 \mathrm{a}$ & $96,2 \mathrm{a}$ & $98,2 \mathrm{a}$ & $100,0 \mathrm{a}$ \\
[hexazinone + diuron] & 105 & $35,2 \mathrm{~d}$ & $75,0 \mathrm{~b}$ & $80,7 \mathrm{~b}$ & $92,7 \mathrm{a}$ & $94,0 \mathrm{a}$ \\
imazapic & 600 & $50,0 \mathrm{~b}$ & $75,0 \mathrm{~b}$ & $80,7 \mathrm{~b}$ & $72,5 \mathrm{~b}$ & $73,7 \mathrm{~b}$ \\
sulfentrazone & 1.440 & $100,0 \mathrm{a}$ & $100,0 \mathrm{a}$ & $100,0 \mathrm{a}$ & $100,0 \mathrm{a}$ & $100,0 \mathrm{a}$ \\
metribuzin & 1.800 & $1,0 \mathrm{f}$ & $10,7 \mathrm{e}$ & $11,7 \mathrm{~d}$ & $15,0 \mathrm{c}$ & $14,2 \mathrm{c}$ \\
trifluralin & 1.920 & $2,2 \mathrm{e}$ & $25,0 \mathrm{~d}$ & $22,5 \mathrm{c}$ & $6,5 \mathrm{~d}$ & $4,0 \mathrm{~d}$ \\
S-metolachlor & - & $0,0 \mathrm{f}$ & $0,0 \mathrm{f}$ & $0,0 \mathrm{e}$ & $0,0 \mathrm{e}$ & $0,0 \mathrm{e}$ \\
testemunha capinada & - & 9,33 & 5,15 & 5,50 & 8,94 & 8,71 \\
\hline CV (\%) & - & & & & &
\end{tabular}

Médias seguidas de mesma letra na coluna não diferem pelo teste de Scott-Knott a 5\% de probabilidade. *DAA: Dias após a aplicação.

A altura das plantas de feijão medida aos 60 DAE, mostrou que todos os herbicidas induziram a redução da altura das plantas (Tabela 3). Os menores níveis na redução da altura das plantas de feijão foram constatados nos tratamentos S-metolachlor, trifluralin e tebuthiuron.

Tabela 3. Estande e altura de plantas de feijoeiro cv. Jalo Precoce após aplicação em préemergência de herbicidas registrados para cultura da cana-de-açúcar. Rio Verde, GO. 2008/2009.

\begin{tabular}{lcccc}
\hline Herbicida & $\begin{array}{c}\text { Dosagem } \\
\left(\mathrm{g} \mathrm{ha}^{-1}\right)\end{array}$ & $10 \mathrm{DAE}^{*}$ & $25 \mathrm{DAE}$ & $60 \mathrm{DAE}$ \\
\cline { 3 - 5 } & 2.500 & $0,2 \mathrm{~d}$ & $0,0 \mathrm{~d}$ & $0,0 \mathrm{f}$ \\
ametryn & 800 & $9,5 \mathrm{a}$ & $30,6 \mathrm{a}$ & $41,4 \mathrm{~b}$ \\
tebuthiuron & 900 & $8,7 \mathrm{a}$ & $28,4 \mathrm{a}$ & $38,9 \mathrm{c}$ \\
clomazone & 112,5 & $0,7 \mathrm{~d}$ & $0,0 \mathrm{~d}$ & $0,0 \mathrm{f}$ \\
isoxaflutole & $2,7 \mathrm{c}$ & $0,0 \mathrm{~d}$ & $0,0 \mathrm{f}$ \\
[hexazinone + diuron $]$ & $237,5+842,4$ & $8,2 \mathrm{a}$ & $7,5 \mathrm{c}$ & $10,3 \mathrm{e}$ \\
imazapic & 105 & $5,5 \mathrm{~b}$ & $19,5 \mathrm{~b}$ & $31,0 \mathrm{~d}$ \\
sulfentrazone & 600 & $0,5 \mathrm{~d}$ & $0,0 \mathrm{~d}$ & $0,0 \mathrm{f}$ \\
metribuzin & 1.440 & $10,2 \mathrm{a}$ & $29,8 \mathrm{a}$ & $45,2 \mathrm{~b}$ \\
trifluralin & 1.800 & $9,2 \mathrm{a}$ & $27,7 \mathrm{a}$ & $46,8 \mathrm{~b}$ \\
S-metolachlor & 1.920 & $10,7 \mathrm{a}$ & $30,3 \mathrm{a}$ & $52,0 \mathrm{a}$ \\
testemunha capinada & - & 8,73 & 7,98 & 8,21 \\
\hline CV $(\%)$ & - & $\mathrm{c}$ ) &
\end{tabular}

Médias seguidas de mesma letra na coluna não diferem pelo teste de Scott-Knott a 5\% de probabilidade. *DAE: Dias após a emergência.

Aos 30 DAE, a matéria verde e a matéria seca das plantas de feijão foram contabilizadas, verificando-se que os herbicidas clomazone, trifluralin, Smetolachlor e tebuthiuron não causaram problemas no acúmulo de fitomassa às 
plantas de feijão (Tabela 4). A redução mais drástica referente ao acúmulo de matéria seca e/ou verde foi verificada quando se utilizou o herbicida imazapic em pré-emergência. Novamente ressalva-se que nos tratamentos metribuzin, ametryn, isoxaflutole e [hexazinone + diuron] não foram contabilizados nenhum valor de matéria verde ou seca, devido à ausência de plantas.

Trinta dias após essa avaliação, registrou-se que os únicos tratamentos que não promoveram redução no aporte de matéria verde ou seca das plantas de feijão foram o trifluralin e o s-metolachlor (Tabela 4). Menores reduções no aporte de fitomassa às plantas de feijão aos 60 DAE foram decorrentes da atividade dos herbicidas tebuthiuron, clomazone e sulfentrazone.

A altura da inserção da primeira vagem das plantas de feijão não foi influenciada pela ação dos herbicidas Smetolachlor e tebuthiuron (Tabela 5). Os herbicidas clomazone e trifluralin promoveram redução significativa na altura de inserção da primeira vagem, sendo que essa avaliação não foi realizada nas parcelas contendo os tratamentos metribuzin, ametryn, isoxaflutole, imazapic, [hexazinone + diuron] e sulfentrazone por não haver plantas vivas no momento da colheita ou pela não formação de vagens nas plantas sobreviventes.

Apenas quatro tratamentos não acarretaram em diminuição no número de plantas por ocasião da colheita, sendo eles: tebuthiuron, S-metolachlor, trifluralin e clomazone (Tabela 5).

Tabela 4. Matéria verde e seca da parte aérea de plantas de feijoeiro cv. Jalo Precoce após aplicação em pré-emergência de herbicidas registrados para cultura da cana-de-açúcar. Rio Verde, GO. 2008/2009.

\begin{tabular}{lccccc}
\hline Herbicida & $\begin{array}{c}\text { Dosagem } \\
\left(\mathrm{g} \mathrm{ha}^{-1}\right)\end{array}$ & \multicolumn{2}{c}{ M. verde $(\mathrm{g})$} & \multicolumn{2}{c}{ M. seca $(\mathrm{g})$} \\
\cline { 3 - 6 } & 2.500 & $0,0 \mathrm{~d}$ & $0,0 \mathrm{e}$ & $0,0 \mathrm{~d}$ & $0,0 \mathrm{~d}$ \\
\hline ametryn & 800 & $22,2 \mathrm{a}$ & $44,0 \mathrm{~b}$ & $3,0 \mathrm{a}$ & $12,9 \mathrm{~b}$ \\
tebuthiuron & 900 & $20,9 \mathrm{a}$ & $35,2 \mathrm{c}$ & $2,8 \mathrm{a}$ & $13,7 \mathrm{~b}$ \\
clomazone & 112,5 & $0,0 \mathrm{~d}$ & $0,0 \mathrm{e}$ & $0,0 \mathrm{~d}$ & $0,0 \mathrm{~d}$ \\
isoxaflutole & 105 & $4,0 \mathrm{c}$ & $30,3 \mathrm{c}$ & $0,5 \mathrm{c}$ & $8,3 \mathrm{c}$ \\
[hexazinone + diuron $]$ & $237,5+842,4$ & $0,0 \mathrm{~d}$ & $0,0 \mathrm{e}$ & $0,0 \mathrm{~d}$ & $0,0 \mathrm{~d}$ \\
imazapic & 600 & $9,8 \mathrm{~b}$ & $23,4 \mathrm{~d}$ & $1,3 \mathrm{~b}$ & $10,7 \mathrm{~b}$ \\
sulfentrazone & 1.440 & $0,0 \mathrm{~d}$ & $0,0 \mathrm{e}$ & $0,0 \mathrm{~d}$ & $0,0 \mathrm{~d}$ \\
metribuzin & 1.800 & $22,8 \mathrm{a}$ & $57,2 \mathrm{a}$ & $3,1 \mathrm{a}$ & $19,1 \mathrm{a}$ \\
trifluralin & 1.920 & $21,3 \mathrm{a}$ & $54,8 \mathrm{a}$ & $2,7 \mathrm{a}$ & $17,8 \mathrm{a}$ \\
S-metolachlor & - & $22,9 \mathrm{a}$ & $56,8 \mathrm{a}$ & $3,1 \mathrm{a}$ & $18,1 \mathrm{a}$ \\
testemunha capinada & - & 11,25 & 8,05 & 8,48 & 12,41 \\
\hline CV $(\%)$ & & &
\end{tabular}

Médias seguidas de mesma letra na coluna não diferem pelo teste de Scott-Knott a 5\% de probabilidade. *DAE: Dias após a emergência.

Os tratamentos S-metolachlor, tebuthiuron, trifluralin e clomazone não promoveram redução na produtividade de grãos de feijão, sendo que a produtividade ficou em torno de $2000 \mathrm{~kg} \mathrm{ha}^{-1}$ (Tabela 5).
Onde se aplicou metribuzin, ametryn, isoxaflutole, imazapic, [hexazinone + diuron] e sulfentrazone a colheita foi completamente inviabilizada, ou seja, não houve a formação de um único grão de 
feijão nessas parcelas. Sikkema et al. (2004) constataram que a aplicação de imazethapyr, herbicida do mesmo grupo químico que o imazapic, em pré-plantio incorporado (PPI) em área cultivada com feijão causou $7 \%$ de injúria visual e reduziu a altura de plantas, a massa seca da parte aérea, e a produtividade de grãos em 8,18 e $12 \%$ na dosagem de $75 \mathrm{~g}$ ha $^{-1}$ e 19,38 e $27 \%$, quando a dosagem do herbicida foi de $150 \mathrm{~g} \mathrm{ha}^{-1}$, respectivamente.

Decorrente da análise desses dados verifica-se que os tratamentos s-metolachlor, tebuthiuron, trifluralin e clomazone apresentaram seletividade satisfatória às plantas de feijoeiro cv. Jalo Precoce. É importante ressaltar que os herbicidas tebuthiuron e clomazone não possuem registro para uso na cultura do feijão, apenas são registrados para uso na cana-de-açúcar. Apesar do mercado de herbicidas na cultura do feijão no Brasil não ser um dos mais atraentes, não estimulando a pesquisa e o desenvolvimento de outras moléculas pelas empresas fabricantes de defensivos agrícolas, é obrigação da pesquisa agrícola pública brasileira, tentar encontrar novas opções de herbicidas para uso nessa cultura (Procópio et al., 2009).

Ressalta-se também, a questão da variabilidade da seletividade entre cultivares de feijão e a questão do residual prolongado desses dois herbicidas (tebuthiuron e clomazone) no solo, como possíveis entraves para o registro desses produtos para uso em campos isolados de produção de feijão. No entanto, para produção integrada de feijão em áreas de cana-de-açúcar esses herbicidas podem ter grande importância, pois diferentemente do trifluralin e do Smetolachlor que são considerados graminicidas, clomazone e tebuthiuron possuem um espectro maior de controle, destacando principalmente a gama de espécies invasoras controladas pelo tebuthiuron.

Tabela 5. Altura da inserção da primeira vagem (AIPV), número de plantas colhidas na área útil da parcela (NPC) e produtividade de grãos de feijoeiro cv. Jalo Precoce após aplicação em préemergência de herbicidas registrados para cultura da cana-de-açúcar. Rio Verde, GO. 2008/2009.

\begin{tabular}{|c|c|c|c|c|}
\hline Herbicida & $\begin{array}{c}\text { Dose } \\
\left(\mathrm{g} \mathrm{ha}^{-1}\right)\end{array}$ & $\begin{array}{l}\text { AIPV } \\
(\mathrm{cm})\end{array}$ & $\begin{array}{c}\mathrm{NPC} \\
\left(\mathrm{pl} .8 \mathrm{~m}^{-2}\right)\end{array}$ & $\begin{array}{l}\text { Produtividade } \\
\qquad\left(\mathrm{kg} \mathrm{ha}^{-1}\right)\end{array}$ \\
\hline ametryn & 2.500 & $0,0 \mathrm{~d}$ & $0,0 \mathrm{c}$ & $0,0 \mathrm{~b}$ \\
\hline tebuthiuron & 800 & $18,2 \mathrm{a}$ & $197,7 \mathrm{a}$ & $2015 \mathrm{a}$ \\
\hline clomazone & 900 & $16,9 \mathrm{~b}$ & $169,7 \mathrm{a}$ & $1731 \mathrm{a}$ \\
\hline isoxaflutole & 112,5 & $0,0 \mathrm{~d}$ & $0,0 \mathrm{c}$ & $0,0 \mathrm{~b}$ \\
\hline [hexazinone + diuron] & $237,5+842,4$ & $0,0 \mathrm{~d}$ & $0,0 \mathrm{c}$ & $0,0 \mathrm{~b}$ \\
\hline imazapic & 105 & $0,0 \mathrm{~d}$ & $0,0 \mathrm{c}$ & $0,0 \mathrm{~b}$ \\
\hline sulfentrazone & 600 & $0,0 \mathrm{~d}$ & $88,0 \mathrm{~b}$ & $0,0 \mathrm{~b}$ \\
\hline metribuzin & 1.440 & $0,0 \mathrm{~d}$ & $0,0 \mathrm{c}$ & $0,0 \mathrm{~b}$ \\
\hline trifluralin & 1.800 & $15,6 \mathrm{c}$ & $199,7 \mathrm{a}$ & 1968 a \\
\hline S-metolachlor & 1.920 & $18,7 \mathrm{a}$ & $193,2 \mathrm{a}$ & $2111 \mathrm{a}$ \\
\hline testemunha capinada & - & $19,3 \mathrm{a}$ & $187,2 \mathrm{a}$ & $2031 \mathrm{a}$ \\
\hline $\mathrm{CV}(\%)$ & - & 4,39 & 10,38 & 11,23 \\
\hline
\end{tabular}

Médias seguidas de mesma letra não diferem pelo teste de Scott-Knott a 5\% de probabilidade. 
Bioensaio em campo com aplicações de herbicidas em pós-emergência

Todos os herbicidas avaliados causaram intoxicação às plantas de feijão, contudo em diferentes níveis de intensidade. Decorridos apenas sete dias da aplicação (DAA) observa-se que os herbicidas metribuzin, [ametryn + trifloxysulfuron sodium], ametryn, 2,4-D, [hexazinone + diuron], [MSMA + diuron] e MSMA promoveram níveis elevados de intoxicação às plantas de feijão, variando de 67,0 a 90,0\% (Tabela 6). Nessa mesma época de avaliação, observou-se que a aplicação de mesotrione resultou em fitotoxicidade de $47,0 \%$. O tratamento que ocasionou o menor nível de injúrias às plantas de feijão, aos 7 DAA, foi o halosulfuron $(6,7 \%)$, fato que se relaciona com o espectro de ação desse herbicida, que se resume ao controle de ciperáceas.
Aos 14 DAA, verificou-se evolução nos sintomas de todos os tratamentos avaliados, sendo que os herbicidas metribuzin, [ametryn + trifloxysulfuron sodium] e [hexazinone + diuron] acarretaram os maiores níveis de intoxicação ao feijoeiro, sendo que nessa avaliação todas as plantas de feijão presentes nas parcelas onde se aplicou metribuzin já se encontravam mortas. O único tratamento que ainda manteve um nível de injúria aceitável nesta avaliação foi o halosulfuron $(17,5 \%$ de fitotoxicidade) (Tabela 6). Todos os demais herbicidas (2,4-D, ametryn, [MSMA + diuron], MSMA e mesotrione) promoveram níveis de intoxicação considerados elevados.

Na última avaliação de fitotoxicidade realizada aos 28 DAA, constatou-se que os todos os tratamentos herbicidas, com exceção do halosulfuron, provocaram a morte de todas as plantas de feijão presentes na área útil das parcelas.

Tabela 6. Fitointoxicação em plantas de feijoeiro cv. Jalo Precoce após aplicação em pósemergência de herbicidas registrados para cultura da cana-de-açúcar. Rio Verde, GO. 2008/2009.

\begin{tabular}{lcccc}
\hline Herbicida & Dosagem & \multicolumn{3}{c}{ Fitointoxicação (\%) } \\
\cline { 3 - 5 } & $\left(\mathrm{g} \mathrm{ha}^{-1}\right)$ & $7 \mathrm{DAA}^{*}$ & $14 \mathrm{DAA}$ & $28 \mathrm{DAA}$ \\
\hline $2,4-\mathrm{D}$ & 1.005 & $76,2 \mathrm{a}$ & $89,5 \mathrm{~b}$ & $100,0 \mathrm{a}$ \\
ametryn & 1.500 & $77,5 \mathrm{a}$ & $90,2 \mathrm{~b}$ & $100,0 \mathrm{a}$ \\
MSMA & 1.440 & $67,0 \mathrm{a}$ & $77,0 \mathrm{c}$ & $100,0 \mathrm{a}$ \\
[MSMA + diuron] & $1.080+420$ & $69,5 \mathrm{a}$ & $85,0 \mathrm{~b}$ & $100,0 \mathrm{a}$ \\
mesotrione & 120 & $47,0 \mathrm{~b}$ & $67,7 \mathrm{c}$ & $100,0 \mathrm{a}$ \\
halosulfuron & 112,5 & $6,7 \mathrm{c}$ & $17,5 \mathrm{~d}$ & $18,7 \mathrm{~b}$ \\
[hexazinone + diuron] & $237,6+842,4$ & $75,2 \mathrm{a}$ & $95,7 \mathrm{a}$ & $100,0 \mathrm{a}$ \\
metribuzin & 1.440 & $90,0 \mathrm{a}$ & $100,0 \mathrm{a}$ & $100,0 \mathrm{a}$ \\
[ametryn + trifloxysulfuron sodium] & $1.280+32,4$ & $82,0 \mathrm{a}$ & $98,5 \mathrm{a}$ & $100,0 \mathrm{a}$ \\
testemunha capinada & - & $0,0 \mathrm{~d}$ & $0,0 \mathrm{e}$ & $0,0 \mathrm{c}$ \\
\hline CV(\%) & - & 7,44 & 4,94 & 3,47 \\
\hline
\end{tabular}

Médias seguidas de mesma letra na coluna não diferem pelo teste de Scott-Knott a 5\% de probabilidade. *DAA: Dias após a aplicação.

A utilização do halosulfuron promoveu pequena redução na altura das plantas de feijão aos 22 DAA (Tabela 7). Ressalta-se que nessa época de avaliação as plantas de feijão alocadas nas parcelas dos tratamentos 2,4-D, ametryn, MSMA, [MSMA + diuron], mesotrione, [hexazinone + diuron], metribuzin e [ametryn + trifloxysulfuron sodium] já se encontravam todas mortas. Cobucci \& Machado (1999) 
relatam que o herbicida imazamox, aplicado em pós-emergência, promoveu redução do porte das plantas de feijão, especificamente, nos cultivares precoces Jalo Precoce e Novo Jalo.
O herbicida halosulfuron acarretou pequena redução no acúmulo de matéria verde nas plantas de feijão aos 22 DAA, porém não sendo significativa em relação à matéria seca (Tabela 7).

Tabela 7. Altura de plantas, matéria verde e seca da parte aérea de plantas de feijoeiro cv. Jalo Precoce, após a aplicação em pós-emergência de herbicidas registrados para uso na cultura da cana-de-açúcar. Rio Verde, GO. 2008/2009.

\begin{tabular}{lcccc}
\hline Herbicida & $\begin{array}{c}\text { Dosagem } \\
\left(\mathrm{g} \mathrm{ha}^{-1}\right)\end{array}$ & $\begin{array}{c}\text { Altura } \\
(\mathrm{cm})\end{array}$ & $\begin{array}{c}\text { M. verde } \\
(\mathrm{g})\end{array}$ & $\begin{array}{c}\text { M. seca } \\
(\mathrm{g})\end{array}$ \\
\cline { 3 - 5 } & $22 \mathrm{DAA}$ & $22 \mathrm{DAA}$ & $22 \mathrm{DAA}$ \\
\hline 2,4-D & 1.005 & $0,0 \mathrm{c}$ & $0,0 \mathrm{c}$ & $0,0 \mathrm{~b}$ \\
Ametryn & 1.500 & $0,0 \mathrm{c}$ & $0,0 \mathrm{c}$ & $0,0 \mathrm{~b}$ \\
MSMA & 1.440 & $0,0 \mathrm{c}$ & $0,0 \mathrm{c}$ & $0,0 \mathrm{~b}$ \\
[MSMA + diuron] & $1.080+420$ & $0,0 \mathrm{c}$ & $0,0 \mathrm{c}$ & $0,0 \mathrm{~b}$ \\
mesotrione & 120 & $0,0 \mathrm{c}$ & $0,0 \mathrm{c}$ & $0,0 \mathrm{~b}$ \\
halosulfuron & 112,5 & $46,2 \mathrm{~b}$ & $88,1 \mathrm{~b}$ & $11,6 \mathrm{a}$ \\
[hexazinone + diuron] & $237,6+842,4$ & $0,0 \mathrm{c}$ & $0,0 \mathrm{c}$ & $0,0 \mathrm{~b}$ \\
metribuzin & 1.440 & $0,0 \mathrm{c}$ & $0,0 \mathrm{c}$ & $0,0 \mathrm{~b}$ \\
[ametryn + trifloxysulfuron sodium] & $1.280+32,4$ & $0,0 \mathrm{c}$ & $0,0 \mathrm{c}$ & $0,0 \mathrm{~b}$ \\
testemunha capinada & - & $50,2 \mathrm{a}$ & $95,1 \mathrm{a}$ & $12,5 \mathrm{a}$ \\
\hline CV(\%) & - & 4,09 & 9,43 & 7,49 \\
\hline
\end{tabular}

Médias seguidas de mesma letra não diferem pelo teste de Scott-Knott a 5\% de probabilidade. *DAA: Dias após a aplicação.

Sendo o único herbicida que não eliminou todas as plantas de feijão, halosulfuron promoveu um aumento na altura de inserção da primeira vagem em relação à testemunha sem herbicida (Tabela 8).

O número de plantas presentes na área útil das parcelas que receberam halosulfuron não diferiu da testemunha sem herbicida, variando de 165 a 179 plantas em $8 \mathrm{~m}^{2}$ (Tabela 8). Também, constatou-se que a produtividade de grãos computada no tratamento halosulfuron $\left(1782 \mathrm{~kg} \mathrm{ha}{ }^{-1}\right)$ diferiu significativamente do tratamento controle (2074 kg ha-1) (Tabela 8).

A partir desses resultados fica evidente que nenhum dos herbicidas avaliados apresentou condições de seletividade para ser utilizado em pós- emergência em um sistema de cultivo integrado de feijoeiro cv. Jalo Precoce, em áreas de produção de cana-de-açúcar. O halosulfuron foi o único que ainda proporcionou possibilidade de produção de grãos ao feijoeiro. Todavia, esse herbicida apresenta espectro de ação de herbicida muito limitado, sendo restrito apenas ao controle de ciperáceas. Dificilmente em áreas de produção de cana-de-açúcar ocorre a presença de plantas daninhas de uma única espécie ou mesmo de uma única família, a não ser em áreas com altíssima infestação de Cyperus rotundus. Assim, tais resultados dificultam a formatação de um sistema integrado de cultivo de feijoeiro cv. Jalo Precoce em áreas de cana-de-açúcar, onde a opção mais utilizada para o controle de 
plantas daninhas seja a aplicação de herbicidas em pós-emergência.

Tabela 8. Altura da inserção da primeira vagem (AIPV), número de plantas colhidas na área útil da parcela (NPC) e produtividade de grãos feijoeiro cv. Jalo Precoce, após a aplicação em pósemergência de herbicidas registrados para uso na cultura da cana-de-açúcar. Rio Verde, GO. 2008/2009.

\begin{tabular}{lcccc}
\hline Herbicida & $\begin{array}{c}\text { Dosagem } \\
\left(\mathrm{g} \mathrm{ha}^{-1}\right)\end{array}$ & $\begin{array}{c}\text { AIPV } \\
(\mathrm{cm})\end{array}$ & $\begin{array}{c}\text { NPC } \\
\left(\mathrm{pl} .8 \mathrm{~m}^{-2}\right)\end{array}$ & $\begin{array}{c}\text { Produtividade } \\
\left(\mathrm{kg} \mathrm{ha}^{-1}\right)\end{array}$ \\
\hline 2,4-D & 1.005 & $0,0 \mathrm{c}$ & $0,0 \mathrm{~b}$ & $0,0 \mathrm{c}$ \\
ametryn & 1.500 & $0,0 \mathrm{c}$ & $0,0 \mathrm{~b}$ & $0,0 \mathrm{c}$ \\
MSMA & 1.440 & $0,0 \mathrm{c}$ & $0,0 \mathrm{~b}$ & $0,0 \mathrm{c}$ \\
[MSMA + diuron] & $1.080+420$ & $0,0 \mathrm{c}$ & $0,0 \mathrm{~b}$ & $0,0 \mathrm{c}$ \\
mesotrione & 120 & $0,0 \mathrm{c}$ & $0,0 \mathrm{~b}$ & $0,0 \mathrm{c}$ \\
halosulfuron & 112,5 & $19,6 \mathrm{a}$ & $179 \mathrm{a}$ & $1782 \mathrm{~b}$ \\
[hexazinone + diuron] & $237,6+842,4$ & $0,0 \mathrm{c}$ & $0,0 \mathrm{~b}$ & $0,0 \mathrm{c}$ \\
metribuzin & 1.440 & $0,0 \mathrm{c}$ & $0,0 \mathrm{~b}$ & $0,0 \mathrm{c}$ \\
[ametryn + trifloxysulfuron sodium] & $1.280+32,4$ & $0,0 \mathrm{c}$ & $0,0 \mathrm{~b}$ & $0,0 \mathrm{c}$ \\
testemunha capinada & - & $14,8 \mathrm{~b}$ & $165 \mathrm{a}$ & $2074 \mathrm{a}$ \\
\hline CV(\%) & - & 3,04 & 6,87 & 16,32 \\
\hline
\end{tabular}

Médias seguidas de mesma letra não diferem pelo teste de Scott-Knott a 5\% de probabilidade.

\section{Conclusões}

Os herbicidas S-metolachlor $(1.920 \mathrm{~g}$ $\left.\mathrm{ha}^{-1}\right)$, tebuthiuron $\left(800 \mathrm{~g} \mathrm{ha}^{-1}\right)$, trifluralin (1.800 $\left.\mathrm{g} \mathrm{ha}^{-1}\right)$ e clomazone $\left(800 \mathrm{~g} \mathrm{ha}^{-1}\right)$ apresentam seletividade satisfatória ao feijoeiro cv. Jalo Precoce, quando aplicados em pré-emergência.

Os herbicidas ametryn $\left(2.500 \mathrm{~g} \mathrm{ha}^{-1}\right)$, [hexazinone + diuron] $\left(237,6+842,4 \mathrm{~g}^{-}\right.$ $\left.{ }^{1}\right)$, metribuzin (1.440 $\left.\mathrm{g} \mathrm{ha}^{-1}\right)$, isoxaflutole (112,5 $\left.\mathrm{g} \mathrm{ha}^{-1}\right)$, sulfentrazone $\left(600 \mathrm{~g} \mathrm{ha}^{-1}\right) \mathrm{e}$ imazapic (105 $\mathrm{g} \mathrm{ha}^{-1}$ ) não foram seletivos ao feijoeiro cv. Jalo Precoce, quando aplicados em pré-emergência.

Os herbicidas MSMA (1.440 $\left.\mathrm{g} \mathrm{ha}^{-1}\right)$, MSMA + diuron $\left(1.080+420 \mathrm{~g} \mathrm{ha}^{-1}\right)$, [hexazinone + diuron] $\left(237,6+842,4 \mathrm{~g}^{\mathrm{h}}\right.$ $\left.{ }^{1}\right)$, metribuzin (1.440 $\left.\mathrm{g} \mathrm{ha}^{-1}\right)$, ametryn (1.500 $\left.\mathrm{g} \mathrm{ha}^{-1}\right)$, [ametryn + trifloxysulfuron sodium] $\left(1.280+32,4 \mathrm{~g} \mathrm{ha}^{-1}\right), 2,4-\mathrm{D}\left(1.005 \mathrm{~g} \mathrm{ha}^{-1}\right)$, mesotrione $\left(120 \mathrm{~g} \mathrm{ha}^{-1}\right)$ e halosulfuron $\left(112,5 \mathrm{~g} \mathrm{ha}^{-1}\right)$ não foram seletivos ao feijoeiro cv. Jalo Precoce, quando aplicados em pós-emergência.

\section{Referências}

CHRISTOFFOLETI, P.J. et al. Carfentrazone-ethyl aplicado em pósemergência para o controle de Ipomoea spp. e Commelina benghalensis na cultura da cana-de-açúcar. Planta Daninha, v.24, n.1, p.83-90, 2006.

COBUCCI, T.; MACHADO, E. Seletividade, eficiência de controle de plantas daninhas e persistência no solo de imazamox aplicado na cultura do feijoeiro. Planta Daninha, v.17, n.3, p.421-432, 1999.

COMISSÃO ESTADUAL DE PESQUISA DE FEIJÃO. Recomendações técnicas para cultivo no Rio Grande do Sul. Santa Maria: UFSM, 2000. 80 p.

FARIS, M.A. et al. Yield stability in intercropping studies of sorghum (Sorghum bicolor) or maize (Zea mays) with cowpea (Vigna unguiculata) or common bean 
(Phaseolus vulgaris) under different fertility levels in Northeastern Brazil. Canadian Journal of Plant Science, v.63, n.4, p.789800, 1983.

FERREIRA, D.F. Sisvar - sistema de análise de variância para dados balanceados. Lavras: UFLA, 1998. 19 p.

FNP CONSULTORIA \& COMÉRCIO. Anualpec. São Paulo: Editora Argos Comunicação, 2007.

FRANCIS, C.A.; PRAGER, G.; TEJADA, $\mathrm{G}$. Effects of relative planting dates in bean (Phaseolus vulgaris L.) and maize (Zea mays L.) intercropping patterns. Field Crops Research, v.5, n.1, p.45-54, 1982.

FUENTES, J.R. et al. Tolerância de cultivares de feijão (Phaseolus vulgaris L.) aos herbicidas alachlor e linuron. Revista Ceres, v.31, n.174, p.136-145, 1984.

HUNGRIA, M. et al. Interação entre microrganismos do solo, feijoeiro e milho em monocultura ou consórcio. Pesquisa Agropecuária Brasileira, v.32, n.8, p.807818, 1997.

KUNKEL, D.L., BELLINDER, R.R., STEFFENS, J.C. Safeners reduce corn (Zea mays) chloroacetanilide and dicamba injury under different soil temperatures. Weed Technology, v.10, n.1, p.115-120, 1996.
NEVES, M.F.; CONEJERO, M.A. Sistema agroindustrial da cana: cenários e agenda estratégica. Economia Aplicada, v.11, n.4, p.587-604, 2007.

PROCOPIO, S.O. et al. Potencial de uso dos herbicidas chlorimuron-ethyl, imazethapyr e cloransulam-methyl na cultura do feijão. Planta Daninha, v.27, n.2, p.327-336, 2009.

PROCÓPIO, S.O.; SILVA, A.A.; VARGAS, L. Manejo e controle de plantas daninhas em cana-de-açúcar. In: VARGAS, L.; ROMAN, E.S. (Eds.). Manual de manejo e controle de plantas daninhas. Bento Gonçalves: Embrapa Uva e Vinho, 2004. p.397-452.

SIKKEMA, P.H. et al. Tolerance of white beans to postemergence broadleaf herbicides. Weed Technology, v.18, n.4, p.893-901, 2004.

SILVA, A.A. et al. Controle de plantas daninhas. Brasília: ABEAS, 2003. p. 260.

VELINI, E.D. et al. Avaliação da seletividade da mistura de oxyfluorfen e ametryne, aplicada em pré ou pósemergência, a dez variedades de cana-deaçúcar (cana-planta). Planta Daninha, v.18, n.1, p.123-134, 2000.

VIGER, P.R., EBERLEIN, C.V., FUERST, E.P. Influence of available soil water content, temperature, and CGA-154281 on metolachlor injury to corn. Weed Science, v.39, n.2, p.227-231, 1991. 